\title{
O DESENHO COMO ATIVIDADE DA IMAGINAÇÃO E CRIAÇÃO NA INFÂNCIA
}

\author{
Fatima Aparecida de Souza Francioli ${ }^{1}$ \\ https://orcid.org/0000-0001-8373-7056 \\ Débora Buss Steinheuser ${ }^{2}$ \\ https://orcid.org/0000-0001-7788-4981
}

RESUMO: Este estudo propôs- se a analisar a função do desenho como atividade criadora da criança, seguindo os princípios da teoria histórico-cultural abordados na obra de Vigotski (2009) "Imaginação e criação na Infância". Conhecer os estágios e os significados dos desenhos infantis são fundamentais para compreender a representação mental dos registros que a criança tem em sua memória. Nessas premissas, foi realizada a coleta de dados, em uma escola pública, com crianças de cinco e oito anos de idade, em que após a contação de uma história da literatura infantil elas realizaram a produção de um desenho referente à história. Com base nos resultados, identificou-se os estágios dos desenhos produzidos pelas crianças e constatou-se que elas necessitam de estímulos para ampliar suas experiências e sua imaginação. Pode-se afirmar que o trabalho com atividades que envolvem o desenho, em virtude da promoção do desenvolvimento intelectual da criança, promove ações que mantêm seu interesse pela atividade criadora.

PALAVRAS-CHAVE: Desenho infantil, Teoria histórico-cultural, Imaginação

\section{DRAWING AS AN ACTIVITY OF IMAGINATION AND CREATION IN CHILDHOOD}

ABSTRACT: This study aimed to analyze the function of drawing as a creative activity of the child, following the principles of historical-cultural theory discussed in the work of Vigotski (2009) "Imagination and creation in childhood." Knowing the stages and meanings of children's drawings are fundamental to understand the mental

\footnotetext{
${ }^{1}$ Doutora em Educação Escolar. Professora do Colegiado de Pedagogia e do Programa Mestrado em Ensino: Formação Docente Interdisciplinar (PPIFOR) da Universidade Estadual do Paraná (UNESPAR) - Campus de Paranavaí/PR - Brasil. fas.francioli@hotmail.com

${ }^{2}$ Mestranda do Programa Mestrado em Ensino: Formação Docente Interdisciplinar (PPIFOR) da Universidade Estadual do Paraná (UNESPAR) - Campus de Paranavaí/PR - Brasil. debora_steinheuser@hotmail.com
} 
representation of the records that the child has in his memory. In these premises was collected data in a public school with children of ages of five and eight years old, in which they drew after the story was told of children's literature. Based on the results, the stages of the drawings produced by the children were identified and they were found to require stimulus to expand their experiences and their imagination. It can be affirmed that the work with activities that involve the drawing by virtue of the promotion of the intellectual development of the child, promotes actions that maintains their interesting by the creative activity.

KEYWORDS: Child's drawing, Historical-cultural theory, Imagination

\section{EL DIBUJO COMO ACTIVIDAD PARA LA IMAGINACIÓN Y LA CRIANZA EN LA INFANCIA}

RESUMEN: Este estudio tiene como objetivo analizar la función del dibujo como una actividad creadora de los niños, siguiendo los principios de la teoría histórico-cultura de la obra de Vigotski (2009) "La imaginación y el arte en la infancia". Conocer las etapas y los significados de los dibujos infantiles son fundamentales para comprender la representación mental de los registros que los niños tienen en su memoria. De acuerdo con lo anterior, fue realizada una recolección de datos, en una escuela pública, con niños de cinco y ocho años de edad, en la cual después de escuchar una historia de literatura infantil realizaron un dibujo. Con base en los resultados, se identificaron cada una de las etapas de los dibujos que fueron producidos por los niños y se constató que estos necesitan estímulos para poder ampliar sus experiencias en virtud al proceso de su desarrollo intelectual, así mismo, el dibujo hace que se promuevan acciones que mantienen su interés por la actividad creadora.

PALABRAS CLAVE: Dibujo infantil. Teoría histórico-cultural. Imaginación

\section{Introdução}

Esta pesquisa propôs-se a analisar como se desenvolvem os estágios do desenho na criança de diferentes idades, observando a manifestação de suas funções psicológicas superiores durante as atividades com o desenho. Sob o aporte teórico da psicologia histórico-cultural, buscou-se estimular o desenho como atividade da imaginação criadora infantil.

Considerando que para Vigotski (2009) o desenho é uma atividade especificamente humana e intrinsecamente relacionada à apropriação da cultura, é preciso compreender que essa apropriação implica em uma parti- 
cipação ativa da criança na cultura, desenvolvendo ela mesma os modos de ver o mundo à sua volta por meio da fala, do sentir e do relacionar-se com os outros. Ninguém cria do nada, tudo que se cria é apropriado na cultura e na história. É na base do trabalho e no que já foi historicamente produzido que se cria e produz o novo.

Todavia, surge uma questão: como ocorre a atividade criadora na criança? Com base na concepção de que o homem cria suas próprias condições de existência a partir das experiências históricas e culturais, pode-se pensar que a criação e a imaginação da criança é instigada por essas condições materiais: "A criação é um processo de herança histórica em que cada forma que sucede é determinada pelas anteriores" (VIGOTSKI, 2009, p. 42). Em outras palavras, a criação da criança não surge do nada, mas depende dos estímulos externos que lhes são oferecidos. Desta forma, qual seriam os motivos de muitos professores não valorizarem o desenho como recurso que pode promover o desenvolvimento intelectual infantil? Para responder a essas questões e observar como ocorrem os estágios do desenho na infância, realizou-se uma investigação com crianças de cinco e oito anos de idade que frequentam, respectivamente, a educação infantil e os anos iniciais do ensino fundamental de uma escola pública.

Nessa direção, o artigo está organizado em três momentos assim distribuídos: no primeiro momento, aborda-se o desenho visto sob o olhar da teoria histórico-cultural; no segundo momento, é analisado como o trabalho com o desenho possibilita o desenvolvimento das funções psicológicas superiores; e no terceiro momento, há apresentação da metodologia e dos dados coletados durante a pesquisa.

Assim sendo, este estudo buscou abordar qual a importância a ser dada ao desenho em sala de aula como um recurso didático e metodológico, o qual pode contribuir para o desenvolvimento intelectual da criança. Uma vez que, considerado como um instrumento produzido socialmente, o desenho necessita de olhares diferenciados para enriquecer a mediação do conhecimento historicamente acumulado.

\section{O desenho sob a luz da teoria histórico-cultural}

Quando se pensa no desenho, logo se imagina a representação de algo expressado em papel, telas de pintura e/ou de outras formas. Sob uma ótica mais minuciosa, o desenho infantil pode revelar ideias, sentimentos, desejos da criança que nem sempre podem ser observados no cotidiano. Por isso, 
conhecer os estágios e os significados dos desenhos infantis é fundamental, pois através deles há a representação mental dos registros da criança em sua memória, sejam elas positivas ou negativas.

Na atualidade, é possível observar que o desenho em sala de aula é utilizado meramente como um passatempo, sem ter uma intencionalidade planejada pelo professor e aplicado como instrumento para preencher espaços, às vezes, com um único objetivo de estimular a coordenação motora. Silva (2002) relata que a atividade gráfica nesses casos deixa de proporcionar a naturalidade da criança, ou a sua real maneira de desenhar, devendo seguir uma ordem de desenhos adequados.

Embora seja frequentemente empregada, a atividade gráfica é equivocadamente valorizada dentro do 'currículo' na educação infantil. Valoriza-se aquilo que pode ficar registrado no papel, para que outras pessoas possam ver não só o trabalho da criança, mas também a atuação da professora. [...]. Não são questionadas as implicações cognitivas, afetivas, motoras e sociais provocadas por tal adestramento (SILVA, 2002, p. 66).

Analisando esse caso pela perspectiva da teoria histórico-cultural, o desenho usado como técnica pode ser um instrumento para observar o desenvolvimento intelectual, social e cultural da criança durante seu processo de aprendizagem. Por isso, a atividade aqui investigada observa as características do desenho, as quais podem apresentar algo sobre a criança, tanto no desenvolvimento das suas funções psicológicas superiores, como seus sentimentos, revelando o âmbito das relações sociais presentes no cotidiano infantil.

Tais observações apoiaram-se nos estudos realizados por Vigotski (2009) encontrados na obra "Imaginação e criação na Infância". O autor ressalta que a criação de uma criança não é algo espontâneo, linear ou natural. Nos comentários de Smolka nessa obra, ela ressalta que Vigotski queria mostrar que o desenvolvimento da criança perpassa o trabalho da construção do homem sobre o próprio homem, ou seja, é sobre as relações sociais que se vai moldando o indivíduo. Isso ocorre num processo dialético, do movimento da história o qual se transforma e, ao mesmo tempo, transforma o homem.

O desenho, mesmo não visto com a devida importância ou significância, faz parte da cultura, é um processo histórico, conhecimento acumulado pela humanidade e permanece até os dias atuais. Para Silva (1998, p. 216) “[...] a criança desenha, porque vive em uma cultura que tem na atividade gráfica uma de suas formas de expressão. O desenvolvimento do grafismo é marcado 
pelas interações sociais, o que equivale a afirmar a sua constituição social [...]". Silva (1998), ainda esclarece em suas pesquisas: em sala de aula, o desenho tem outras finalidades e, por isso, acaba perdendo a atividade promotora do desenvolvimento cognitivo, afetivo e social, sendo enfatizado apenas o treino motor da criança, ignorando o papel que o outro desempenha.

Nessa direção, Duarte (1996) apresenta um entendimento mais completo à luz da teoria histórico-cultural ao preocupar-se com o fato de os professores buscarem conhecer uma teoria para fundamentar seu trabalho pedagógico.

Significa, dentre outras coisas, considerar que o indivíduo não pode elaborar seu conhecimento individual a não ser apropriando-se do conhecimento historicamente produzido e socialmente existente. [...] $\mathrm{O}$ indivíduo humano se faz humano apropriando-se da humanidade produzida historicamente. $O$ indivíduo se humaniza reproduzindo as características historicamente produzidas do gênero humano (DUARTE, 1996, p. 35).

Isso pressupõe que se apropriar da cultura já produzida pela humanidade é indispensável para apreender os conhecimentos historicamente desenvolvidos pela humanidade. No caso específico desta pesquisa, o desenho, como atividade cultural, necessita de outra pessoa para estimular o processo do desenvolvimento, proporcionando experiências com enriquecimento de atividades para a criança. Oliveira $(1996$, p. 56) ressalta a necessidade do outro na promoção das funções psicológicas superiores:

[...] é necessário postular relações interpessoais: a interação do sujeito com o mundo se dá pela mediação feita por outros sujeitos. Do mesmo modo que o desenvolvimento não é um processo espontâneo de maturação, a aprendizagem não é fruto apenas de uma interação entre indivíduos e o meio. A relação que se dá na aprendizagem é essencial para a própria definição desse processo, que nunca ocorre no indivíduo isolado (OLIVEIRA, 1996, p. 56).

Ao considerar as características diferentes do desenho em cada período, Vigotski $(2009$, p. 19) relata: “[...] cada período da infância possui sua forma característica de criação", enfatizando que imaginar e desenhar não são apenas um divertimento da mente, mas sim uma função vital necessária, conforme aponta a concepção histórico-cultural. 
Vigotski (2009, p. 26) complementa:

[...] as imagens da fantasia servem de expressão interna dos nossos sentimentos. A desgraça e o luto de uma pessoa são marcados com a cor preta; a alegria, com a cor branca; a tranquilidade, com a cor azul; a rebelião, com o vermelho.

Essa passagem confirma a real importância em aprofundar as funções qualitativas do desenho podendo proporcionar à criança em período de desenvolvimento, ressaltando que esse recurso não é apenas promotor de coordenação motora, mas também do desenvolvimento das funções psicológicas superiores.

\section{O trabalho com desenho e o desenvolvimento das funções psicológicas superiores}

Em relação às funções psicológicas superiores, vale ressaltar quais são elas, como se desenvolvem, relacionando-as com o papel da atividade gráfica nesse processo de desenvolvimento psicológico, considerado fundamental para a aquisição do conhecimento.

Vigotski (2001) denomina de Funções Psicológicas Superiores (FPS) aquelas funções mentais que caracterizam o comportamento consciente do homem como: atenção voluntária, memória, linguagem, pensamento, imaginação, abstração e outras. Essas funções, em sua origem, são consideradas sociais e estão interligadas; no entanto, para se efetivarem, precisam ser mediadas pelo outro.

Silva (2002, p. 27-28), sob a perspectiva histórico-cultural, considera as funções psicológicas um processo em que: "As funções psicológicas superiores inicialmente ocorrem ao nível interpsíquico, isto é, entre pessoas, e então passam a dar-se ao nível intrapsíquico, o que significa que são internalizadas pelo sujeito". Ou seja, seguindo os critérios de um trabalho socializado para uma internalização individual.

Para Vigotski (2009) a importância da estimulação, da imaginação e criação, o que pode ser transcrito no desenho, permite verificar seus sentimentos, sua criatividade, memória, imaginação, ou seja, seu desenvolvimento. Para isso, o autor ressalta a significância das experiências vividas.

Assim, faz-se importante o papel e as intenções do professor mediante ao que será proposto aos alunos em relação à atividade gráfica. 
O intercâmbio entre a professora e as crianças é muito rico, porque permite a troca de experiências gráficas em um plano bastante informal e lúdico. As interferências no desenho da criança geram mudanças no próprio desenho e em seu autor. Graficamente, a criança tem possibilidades de acrescentar detaIhes e/ou figuras inteiras ao seu trabalho, gerando novas formas. $E$ as alterações repercutem nos processos psíquicos envolvidos na execução do grafismo: percepção, atenção, memória e conceitualização (SILVA, 2002, p. 90).

Com essa proposta, percebe-se que diversas funções psicológicas superiores são desenvolvidas quando a atividade pedagógica do professor está relacionada com o desenhar de maneira que contribua qualitativamente no processo de desenvolvimento da criança.

Oliveira (1996, p. 56), relata que as funções psicológicas superiores, em sua constituição, envolvem: "consciência, intenção, planejamento, ações voluntárias e deliberadas, dependem de processos de aprendizagem". Dessa maneira, o desenho, como um recurso pedagógico, auxilia a criança a aprimorar seus conhecimentos e estimula sua capacidade psíquica.

Para que fique explícita a importância do desenhar no desenvolvimento das funções psicológicas superiores, será exposta a relevância dessa atividade.

Pode-se considerar em primeira instância, a direta relação ao aprimoramento da imaginação. No momento em que a criança colocar o lápis no papel com o intuito de fazer um desenho, ela começará a usar a sua imaginação para criar algo novo, realizando uma atividade criadora, a qual deve ser considerada uma atividade humana. Na atividade, Coutinho; Zanella (2008) em pesquisas especificas sobre o desenho na perspectiva histórico-cultural, relatam o que absorveram das palavras de Vigotski (1998):

[...] compreende imaginação como sinônimo de fantasia e a atividade criadora como a objetivação da imaginação; sendo assim, toda realização humana é criadora. Partindo desta compreensão, entende-se que desde a infância já existem atividades criadoras, como nas brincadeiras e desenhos infantis (NATIVIDADE et al, 2008, p. 12).

Ao desenhar, a criança utiliza a sua imaginação decorrente do acúmulo de experiências e, segundo Vigotski (2009, p. 25): “[...] a imaginação é uma condição totalmente necessária para quase toda atividade mental humana". Dessa forma, o ato de desenhar seria uma forma de exercitar a imaginação, 
consequentemente uma forma de estimular a criação, o novo, ação essa que se realiza a todo o momento.

Nesse sentido, Petrovsky (1985, p. 181), ressalta os processos fundamentais da imaginação: "Esse é um aspecto indispensável para o trabalho artístico, de desenho, científico, literário, musical e, em geral, para toda atividade criadora". Assim, ao desenhar, a criança está criando algo novo, transferindo para o papel aquilo que já fora internalizado do mundo exterior. Além disso, Petrovsky (1985, p. 182), completa: “A imaginação é a capacidade de criar novas imagens sensoriais ou racionais na consciência humana, com o intuito de transformar as impressões recebidas em realidade". Mais importante ainda é relacionar a importância da imaginação em crianças menores, como cita Petrovsky (1985), principalmente em idade pré-escolar, na qual a imaginação amplia a fantasia, condição para a assimilação das experiências sociais.

Para Vigotski (2009, p. 17), tudo que foi acumulado durante o desenvolvimento não foi esquecido, mas permanece, criando algo novo "É essa capacidade de fazer uma construção de elementos de combinar o velho de novas maneiras, que constitui a base da criação", ou seja, um conhecimento dialético nunca tem fim, sempre haverá algo novo a ser estudado, não ignorando o que já se sabe. Ao relatar diretamente sobre a criatividade nítida nos desenhos, faz-se fundamental descrevê-la que, como dependente de um convívio social, a criança será mais ou menos criativa dependendo dos estímulos e do meio social, como relata Mozzer; Borges (2008, p. 1):

\footnotetext{
É oportuno lembrar que criatividade tem sido apontada, pelo senso comum, como um fenômeno mágico e misterioso, que acontece no homem independentemente das circunstâncias e do meio no qual ele está inserido. Este pensamento não aconteceu nem alcançou tal hegemonia por acaso. Vários são os autores (Amabile 1989, De La Torre 2005, Runco, 1996) que concordam com o fato de que a criatividade faz parte da natureza humana e, portanto, irá se desenvolver em maior ou menor grau dependendo das condições ambientais e sociais. Neste caso a cultura interfere nos níveis de criatividade, mas não na sua origem.
}

Nesse sentido, o desenho está diretamente entrelaçado à criatividade, ao papel do outro e ao meio social, cultural e histórico em que o indivíduo está inserido, logo, ele deve ser cuidadosamente mediado de maneira a contribuir para a amplitude da criação e do desenvolvimento das funções psicológicas superiores, pois em alguns casos, se não houver a mediação intencional, o que poderia ser estimulado, torna-se prejudicial na ação do desenhar. 
Diante dos fatores benéficos do desenho para as funções psicológicas superiores, faz-se importante relatar seu comprometimento com a linguagem, afinal, no momento em que a criança desenha, sua fala organiza o desenho.

Enquanto desenha, a criança fala. Nomeia sua produção quando uma pessoa pergunta o que é e também sem que haja qualquer indagação a esse respeito. Quando alguém pergunta à criança O que você está desenhando?. A criança geralmente nomeia as marcas no papel, atribuindo-lhes significado no momento em que é feito o questionamento (SILVA, 1998 p. 213).

Sendo assim, é possível compreender a importância do desenho na aquisição da linguagem e no seu desenvolvimento, levando a criança a ter autonomia, podendo enquanto desenha relatar o que está sendo exposto no papel, bem como ampliar seu vocabulário e a troca de informações entre indivíduos. Antes de colocar sua criatividade e imaginação em uma folha de papel, é mentalmente ordenado todos os comandos do desenho pela fala.

O enunciado verbal organiza e é organizado pelo desenho. Falar a respeito da produção gráfica é também pensá-la. A linguagem verbal tem função de planejar a elaboração do grafismo; a criança pode antever seu produto, verbalizar o que pretende desenhar e mantê-lo ou modificá-lo antes e/ou depois de iniciar sua execução (SILVA, 1998 p. 215).

Em relação a tal contexto como um dos influenciadores da linguagem e do pensamento, o desenho se faz presente, atribuindo ao mesmo uma significância relevante, e deve ser mais adaptado às aulas, principalmente na educação infantil, base para todo ensino e aprendizagem.

A representação gráfica pode ser considerada também o início da escrita, no qual pode-se registrar e mostrar em sua rica experiência signos mediadores que podem ser anteriores a escrita, assim explicitado por Luria (2010, p. 174):

A fase pictográfica do desenvolvimento da escrita baseia-se na rica experiência dos desenhos infantis, os quais em si mesmos, não precisam desempenhar a função de signos mediadores em qualquer processo intelectual. Inicialmente o desenho é brincadeira, um processo autocontido de representação; em seguida, o ato completo pode ser usado como estratagema, um meio para o registro. Mas pelo fato de a experiência direta do desenho ser tão rica, frequentemente deixamos de obter, da criança, a fase 
pictográfica da escrita em sua forma pura. O desenho como meio é muito frequentemente misturado ao desenho como processo autocontido e sem mediação.

É possível afirmar que enquanto a criança ainda não sabe escrever palavras, o desenho surge como auxilio para orientá-la ou ainda recordá-la de algo, afirmando assim que a escrita - a princípio - depara-se com as representações gráficas, ou seja, no início o desenho atua como estrutura, cuja função é o de promover aquilo que a escrita posteriormente irá fazer. Em outras palavras, o desenho age como signo auxiliar da memória, orientando a criança que ainda não é apta na escrita com letras com aquilo que ela domina: o desenho. Vigotski (2009, p. 62), enfatiza: "[...] as forças criativas da criança não se concentram por acaso no desenho, mas porque é o desenhar que, nessa idade, oferece-lhe a possibilidade de expressar com mais facilidade aquilo que domina".

Ao trabalhar com atividades que envolvem o desenho em virtude da promoção do desenvolvimento intelectual da criança, com objetivos qualitativos para a ampliação das funções psicológicas superiores, o professor promove ações que mantêm seu interesse pela atividade criadora.

\section{Apresentação da metodologia e análise dos dados coletados com o desenho infantil}

Ao longo de todo o período de pesquisa, pode-se considerar que a fundamentação teórica estudada foi a referência para o desenvolvimento da prática conforme objetivo proposto. Após o estudo teórico, ficou clara a importância de se trabalhar com a atividade gráfica de maneira objetivada em sala de aula. Isso permitiu buscar resultados na prática, ou seja, a coleta de dados por meio dos desenhos de crianças que frequentam a educação infantil e o terceiro ano do ensino fundamental de uma escola pública; as idades correspondem respectivamente a cinco anos e oito anos de idade.

As atividades foram desenvolvidas da seguinte maneira: contava-se uma história da literatura infantil, escolhida de acordo com a idade das crianças e, em seguida, era solicitado que as crianças desenhassem o que tinham entendido ou o que mais gostaram da história. Depois, perguntava-se individualmente o que tinham desenhado, anotando-se a descrição fornecida pelas crianças das suas representações gráficas. É importante salientar a observação de todo o processo do desenho, desde a busca da criança em olhar o livro da história contada para ver as imagens ou ignorá-lo. Todo processo de coleta foi 
registrado para que ao longo da pesquisa pudesse ser analisado e comparado à obra de Vigotski (2009) e seus pressupostos teóricos.

Para a análise, foram separados cinco desenhos de alunos com idades de cinco anos e outros cinco desenhos com crianças de oito anos. Para manter os seus anonimatos, foram denominadas por numerais: crianças 1, 2, 3, 4 e 5 da educação infantil e, crianças 1, 2, 3, 4 e 5 do ensino fundamental I.

A história escolhida para a contação do desenho foi: "Chapeuzinho Vermelho e a preservação do bosque", da autora Naira Gomes dos Santos (2011). Durante a leitura, eram mostradas as imagens da obra às crianças para terem referências ao desenhar.

Ao término da história, foi proposto que desenhassem o que mais gostaram. As crianças recebiam uma folha de papel sulfite e lápis de cor para desenhar. O livro utilizado na contação ficava à disposição das crianças.

Em consonância com o capítulo O desenhar na infância de Vigotski (2009), que contempla exclusivamente as quatro fases dos estágios: estágio de esquemas; estágio do surgimento do sentimento da forma e da linha; representação verossímil e representações plásticas, é que foram analisarados os resultados dos desenhos das crianças.

Os estágios são assim nominados por Vigotski: estágio de esquemas; nesse estágio a criança desenha o que ficou evidente sobre o objeto, não busca estar olhando o mesmo ou fazer uma cópia, mas sim representar o que internalizou e apresenta o resultado de uma representação em que aparece, muitas vezes, apenas a cabeça e as pernas, não dando importância aos detalhes.

Vigotski (2009, p. 107) ressalta como resultado desses primeiros desenhos:

Então, o resultado é o que se chama corretamente de desenho de raios X. [...] Partes grandes do corpo humano, como o torso, frequentemente estão ausentes no desenho infantil; as pernas crescem a partir da cabeça; o mesmo ocorre com os braços; as partes são unidas, muitas vezes, não na ordem em que a criança pôde observar numa figura humana.

Assim, foi possível compreender que esses primeiros desenhos não buscam padrões realistas. A perfeição não é aliada, a criança busca representar o essencial para si.

No segundo estágio denominado de surgimento do sentimento da forma e da linha, há desenhos ainda sem o realismo como foco, porém apresentam mais detalhes, em busca de uma essência mais realista. 
No terceiro estágio nomeado como da representação verossímil, aparecem desenhos com contornos que remetem à aparência do real e, assim, aos poucos o desenho infantil vai desaparecendo. Vigotski (2009) ressalta: são poucas as crianças que avançam dessa fase, podendo ser considerada a falta de estímulos como um interruptor do desenhar.

Para Vigotski (2009, p. 110) no quarto estágio das representações plásticas, as "partes isoladas do objeto são representadas em relevo, com ajuda da distribuição da luz e da sombra; surge a perspectiva; transmite o movimento e, mais ou menos, a impressão plástica completa que se tem do objeto". Nesse estágio, é preciso ter os estímulos necessários para que a criança persiga na criação artística, para não se tornar um passatempo ou apenas uma atividade de coordenação motora, mas que possam estar relacionadas com o desenvolvimento das funções psicológicas superiores da criança.

A seguir, há a análise dos desenhos das crianças da educação infantil e das do 3 o ano do ensino fundamental.

\section{Figura 1: desenho da criança 1 da educação infantil- 5 anos de idade}

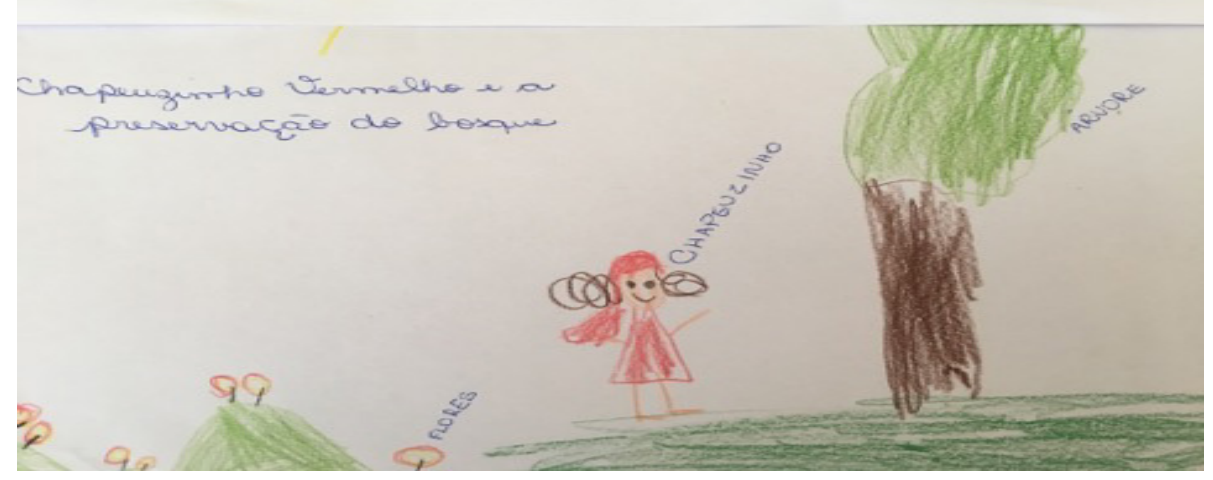

Fonte: Autoras, 2018

A criança 1 da educação infantil, desenhou o que mais ficou evidente na história, como uma menina que utiliza um gorro de cor vermelho, a qual está em um bosque representado por uma árvore e muitas flores. É importante ressaltar que durante a produção do desenho, as crianças dessa turma desenharam por memória, como cita Vigotski, não utilizaram o livro para se embasarem e utilizaram o que ficou registrado na memória sobre a história. De acordo com as análises de Vigotski (2009), tal desenho pode ser conside- 
rado como o segundo estágio do desenho denominado de "surgimento do sentimento da forma e da linha":

[...] ele se caracteriza por um número bem maior de detalhes, por uma disposição mais verossímil de partes isoladas do objeto: ocultações impressionantes como o torso não são mais percebidas; todo o desenho aproxima-se da aparência real do objeto (VIGOTSKI, 2009, p. 110)

Pode-se perceber que a criança 1 da educação infantil já perpassou o primeiro estágio de esquemas para uma fase em que há mais detalhes, permitindo identificar características de fácil compreensão em vista do real.

\section{Figura 2: desenho da criança 2 da educação infantil- 5 anos de idade}

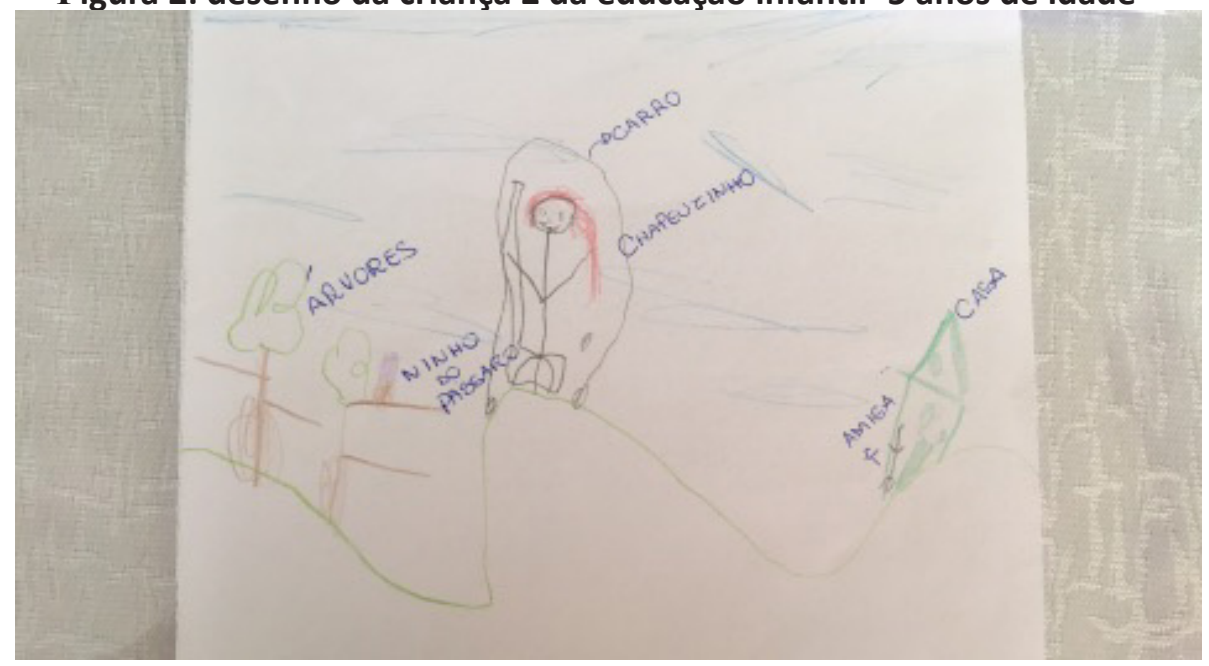

Fonte: Autoras, 2018

A criança 2 da educação infantil representou em seu desenho a personagem Chapeuzinho Vermelho compreendida pelo gorro vermelho em sua cabeça, colocando-a dentro de um carro. Além disso, desenhou uma casa e dentro da mesma um corpo que pode ser percebido como de uma pessoa. Pode-se considerar que essa criança está no primeiro estágio dos desenhos, a denominada de "estágio de esquemas", assim definido por Vigotski (2009, p. 106-107) “Na figura humana, é comum representar a cabeça, as pernas, frequentemente os braços e o torso. A representação da figura humana 
limita-se a isso". Segundo os pressupostos desse estágio, é visível que essa criança caracteriza a figura humana com um círculo o qual representa o rosto apoiado em uma linha correspondente ao corpo, como os desenhos raios $\mathrm{X}$. Além disso, ela usou a imaginação, colocando a Chapeuzinho Vermelho dentro de um carro e outra pessoa dentro da casa. A característica deste estágio é o desenho de memória:

Ela desenha o que sabe sobre a coisa; o que lhe parece mais essencial na coisa, e não aquilo que vê ou que imagina sobre a coisa. Quando a criança vê um cavaleiro montado de perfil, desenha as duas pernas, apesar de apenas uma perna estar visível. Quando desenha uma figura humana de perfil, faz os dois olhos (VIGOTSKI, 2009, p. 107).

Vigotski (2009), também observou que crianças com a mesma faixa etária podem estar em estágios diferentes, evidenciando como o meio social em que vivem pode interferir, pois os estímulos contam muito para o desenho. Dessa forma, não é correto dizer que uma criança esteja atrasada, em casos de crianças com a mesma idade estarem em estágios distintos. Vigotski (2009, p. 112) ressalta este ponto importante: "Isso demonstra com toda a segurança que a diferença na representação não é condicionada ao conteúdo e ao caráter do tema do desenho, mas está relacionada à evolução por que passa a criança"

\section{Figura 3: desenho da criança 3 da educação infantil- 5 anos de idade}

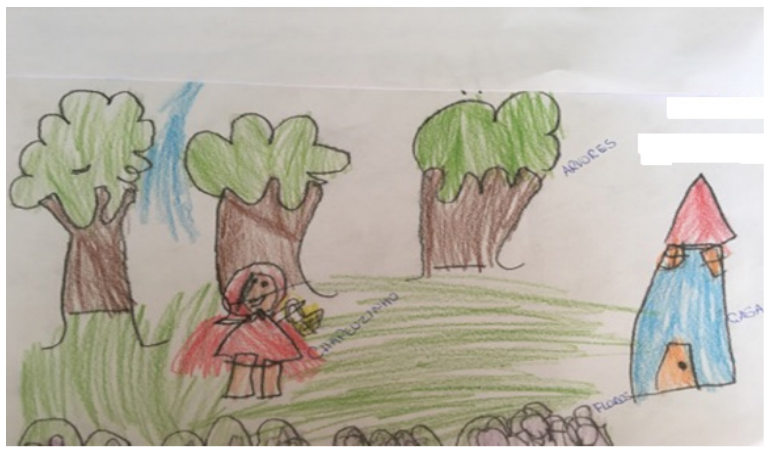

Fonte: Autoras, 2018

A criança 3 da educação infantil, representou em seu desenho o bosque, a personagem Chapeuzinho Vermelho e sua casa. É possível perceber um número maior de detalhes em seu desenho, traços que alcançaram características do real, como por exemplo as árvores, os diferentes troncos, 
os galhos. A Chapeuzinho Vermelho está representada com o gorro vermelho e a cesta no braço, demonstrando mais detalhes do corpo humano e a casa contém características de uma casa real. Nesse caso, a criança está no segundo estágio do "surgimento do sentimento da forma e da linha".

Nesse segundo estágio de desenvolvimento do desenho infantil, percebemos, por um lado, a mistura da representação formal com a esquemática- são ainda desenhos-esquemas- e, por outro, encontramos rudimentos da representação parecida com a realidade (VIGOTSKI, 2009, p. 110).

Foi possível constatar a produção das crianças por memória do que ficou marcado sobre a história, sem precisar folhear novamente o livro para relembrar os desenhos.

Durante o contexto exposto no capítulo, Vigotski (2009, p. 107) descreve o fato de um psicólogo que pediu a uma criança que desenhasse sua mãe que estava posicionada ao seu lado, em nenhum momento a criança a olhou, apenas desenhou o que estava marcado em sua mente de acordo com as suas características.

\section{Figura 4: desenho da criança 4 da educação infantil- 5 anos de idade}

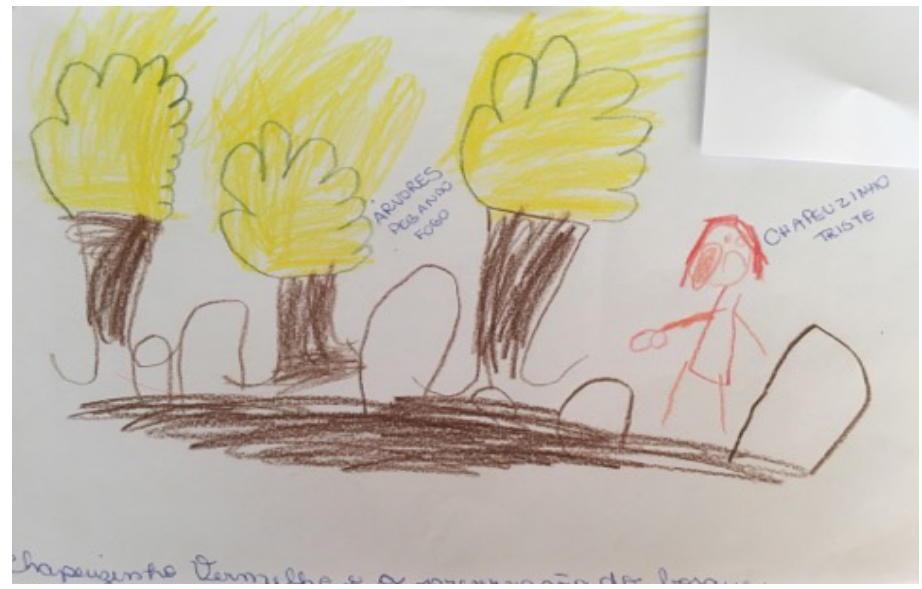

Fonte: Autoras, 2018

A criança 4 da educação infantil caracterizou a história de forma que apareceu a personagem principal. A personagem Chapeuzinho Vermelho, predominante em todos os desenhos, porém com traços de desenho de esquema, ou seja, o primeiro estágio de esquemas, com o torso retangular, braços 
e pernas representados apenas por uma linha. É perceptível: a característica que ficou marcante na personagem é o gorro vermelho ilustrado pela criança.

Para Vigotski (2009, p. 109) essas características demonstram: “[...] o desenho da criança é enumeração, ou melhor, uma narração gráfica sobre o objeto representado", dito em outras palavras, a criança, nesse estágio, desenha o que é mais fácil ao seu ver: "O rosto redondo com duas linhas que o sustentam corresponde ao que é fácil e cômodo para a criança fazer" (VIGOTSKI, 2009, p.108). No contexto da história contada, o bosque onde a Chapeuzinho Vermelho sempre passeava fora queimado. Assim, a criança relata graficamente árvores com a cor amarela, para significar que estão em chamas e, ao reparar no rosto da personagem, é possível perceber um semblante triste. Em comentários, Smolka (2009 p. 109) descreve:

Os traços no papel constituem, assim, os primórdios de uma narração gráfica. [...] A narração e a dramatização encontram-se intrinsecamente relacionadas ao gesto que marca o movimento do corpo e as ações da criança pequena no papel.

Esse pensamento expressa o comportamento das crianças que, ao serem questionadas sobre o que haviam desenhado, relatam o momento em que Chapeuzinho Vermelho estava triste, pelo fato de a floresta estar em chamas.

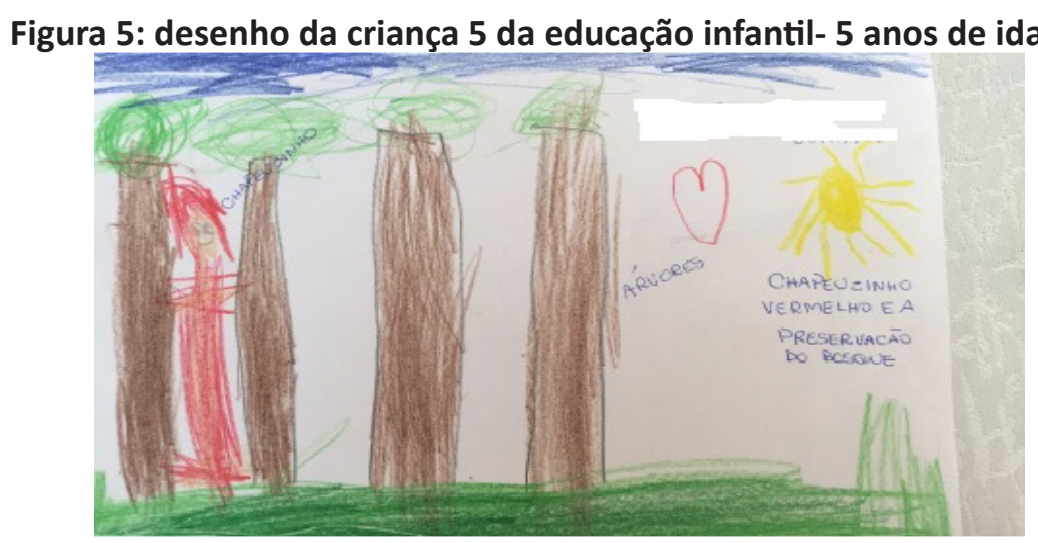

Fonte: Autoras, 2018

O desenho acima analisado, em sua representação gráfica sobre a história, pode ser considerado como pertencente ao estágio de esquema, ou seja, o primeiro estágio, pois ao observá-lo atentamente, em especial a figura 
humana, que pelas cores usadas seria a personagem Chapeuzinho Vermelho, apresenta um traçado característico de seres esquemáticos, ou seja, apenas a cabeça e os traços a sustentam. Nas árvores é possível observar que a criança desenhou o que julgou necessário a representação de uma árvore. Nesse caso, Vigotski (2009, p. 107) afirma: "Ela desenha o que sabe sobre a coisa, o que lhe parece mais essencial na coisa, e não aquilo que vê ou que imagina sobre a coisa". Numa situação próxima a essa, Vigotski (2009) relata o fato de um estudioso que ao perguntar a uma criança o porquê de seu desenho ter apenas a cabeça e as pernas, ouviu que era o suficiente para ver e ir passear. Nesse estágio, as quantidades de detalhes não são levadas em consideração.

A respeito dos desenhos das crianças da educação infantil, aqui analisados, pode-se considerar que, por estarem no mesmo espaço escolar e vivenciando as mesmas práticas docentes, apresentaram os mesmos estágios, sendo uns no primeiro e outros no segundo.

Paralelamente à coleta de desenhos da educação infantil, foram coletados desenhos de crianças que frequentavam o terceiro ano do ensino fundamental I, na faixa etária de oito anos. A seguir, serão analisados cinco desenhos referentes à mesma história contada para as crianças da educação infantil: "Chapeuzinho Vermelho e a preservação do bosque". Utilizou-se a mesma estratégia da contação da história, elaboração de desenhos individuais, anotando em seguida o que haviam desenhado. As crianças serão citadas como: criança 1, 2, 3, 4 e 5 seguindo os respectivos desenhos.

\section{Figura 6: desenho da criança 1 do ensino fundamental- 8 anos de idade}

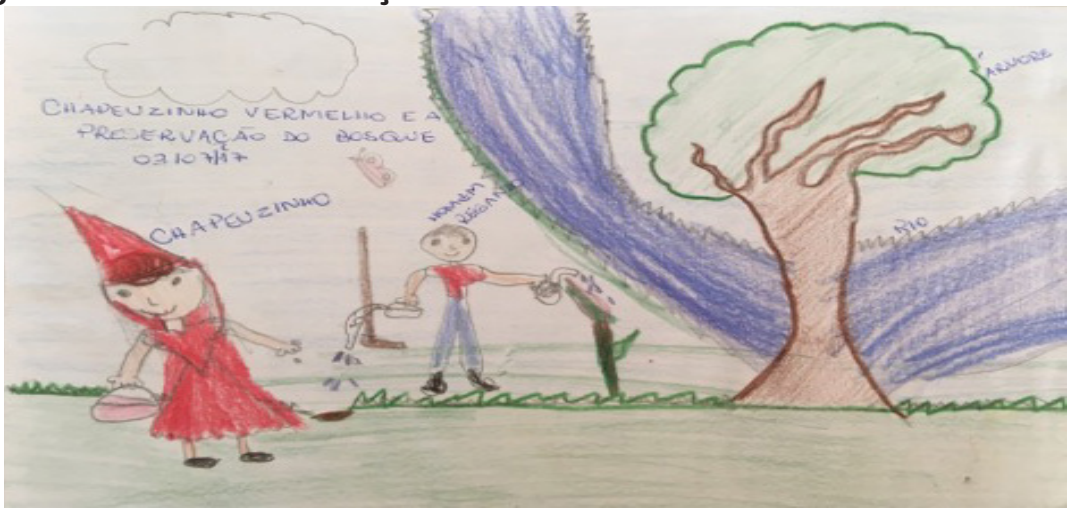

Fonte: Autoras, 2018

O desenho da criança 1 do ensino fundamental pode ser analisado como pertencente ao terceiro estágio, definido como "forma perceptível nas 
figuras humanas". Tais figuras apresentam contornos e assemelham-se com o real. Também aparece um número maior de detalhes, como se pode constatar nas mãos dos personagens: todos os dedos desenhados, o corpo já tem uma estrutura aproximada da estrutura corporal humana e o aparecimento do pescoço como sustentação do corpo. Para Vigotski (2009, p. 110), essas características demonstram:

O desenho tem uma aparência de silhueta ou de contorno. A criança ainda não transmite a perspectiva, a plasticidade do objeto; o objeto ainda é delineado sobre o plano, mas, em geral, ela apresenta-o de forma verossímil e real, próximo de sua verdadeira aparência.

Assim como nas figuras humanas, é possível observar a representação da árvore com tronco e galhos tortuosos, seguindo a linha da realidade.

\section{Figura 7: desenho da criança 2 do ensino fundamental- 8 anos de idade}

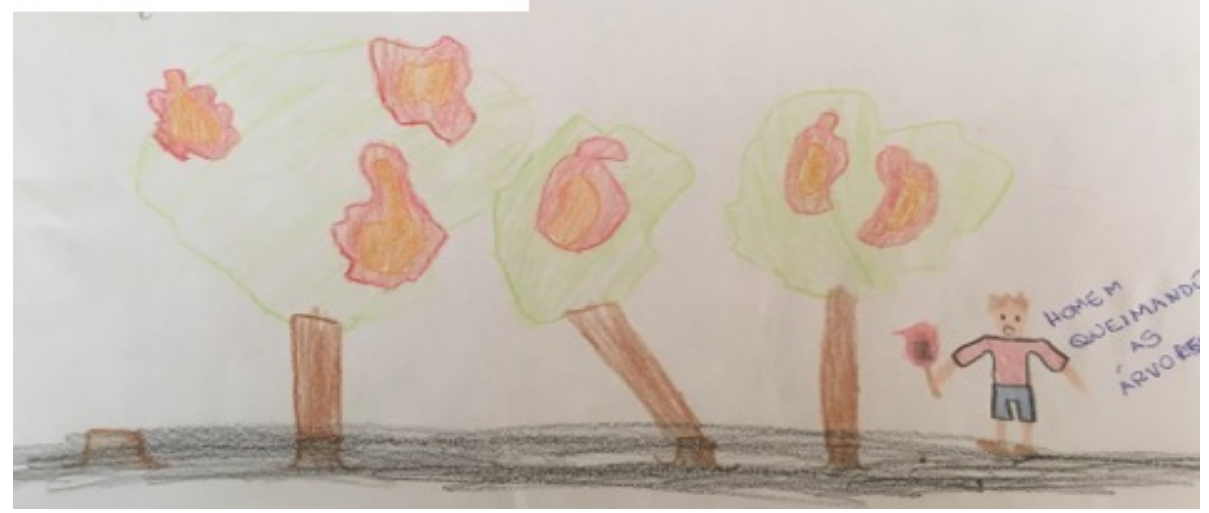

Fonte: Autoras, 2018

A criança 2 do ensino fundamental tem em seu desenho características do segundo estágio. Seguindo os pressupostos teóricos apresentados por Vigotski (2009), diferentemente da maioria das crianças, essa não desenhou a personagem Chapeuzinho Vermelho, mas sim o homem que ateou fogo à 
floresta, como foi relatado na história. As características do homem são desenhos-esquemas, em que há sim mais detalhes, porém os detalhes ainda não são suficientemente ricos para serem considerados como terceiro estágio. É de grande valia ressaltar que isso não significa que o desenho esteja errado, dado ao fato de que se trata de uma criança de 8 anos, uma vez que se pode afirmar que o relevante são os estímulos, o convívio social e os interesses da criança:

Dos dados apresentados pelo autor pode-se ter uma impressão a respeito da distribuição dos quatro estágios por idade: vemos que as crianças de seis anos estão todas no primeiro estágio de esquema puro. A partir dos 11 anos, esse estágio é encontrado com menos frequência; o desenho sofistica-se, e, a partir dos 13 anos, surge o desenho real, no sentido completo e preciso da palavra (VIGOTSKI, 2009, p. 115).

Ou seja, mesmo a criança tendo 8 anos, ela pode encontrar-se nos primeiros estágios, pois, apenas com 11 anos de idade esses tipos de desenhos são vistos com menos frequência e é considerável a estimulação. Além disso, Vigotski (2009 p. 108) esclarece: "Obviamente, as limitações técnicas contribuem para esta pobreza de elaboração que acontece devido à ausência de um objeto artístico sério".

\section{Figura 8: desenho da criança 3 do ensino fundamental- 8 anos de idade}

Fonte: Autoras, 2018 
A criança 3 do ensino fundamental caracterizou em seu desenho a personagem principal. Há erros de proporções, mas segundo Vigotski (2009 p. 112):

[...] os desenhos que pertencem ao terceiro estágio mostram contornos planos da imagem que representa de modo verossímil a aparência real do objeto. Com alguns erros e desproporções, a criança torna-se realista, desenha aquilo que vê, transmite a pose, o movimento, leva em conta o ponto de observação; o esquema não está mais no desenho.

Existem detalhes a mais no desenho, os dedos das mãos, os troncos das árvores. É possível ressaltar que realmente muitas das informações descritas na teoria são perceptíveis na prática, como por exemplo, os desenhos realizados na educação infantil; as crianças não tinham o interesse de ver a história para desenhá-la. Considerado o desenho de memória, no entanto, os alunos do terceiro ano fundamental solicitavam a todo o momento olhar novamente as páginas e desenhar de acordo com o livro.

\section{Figura 9: desenho da criança 4 do ensino fundamental- 8 anos de idade}

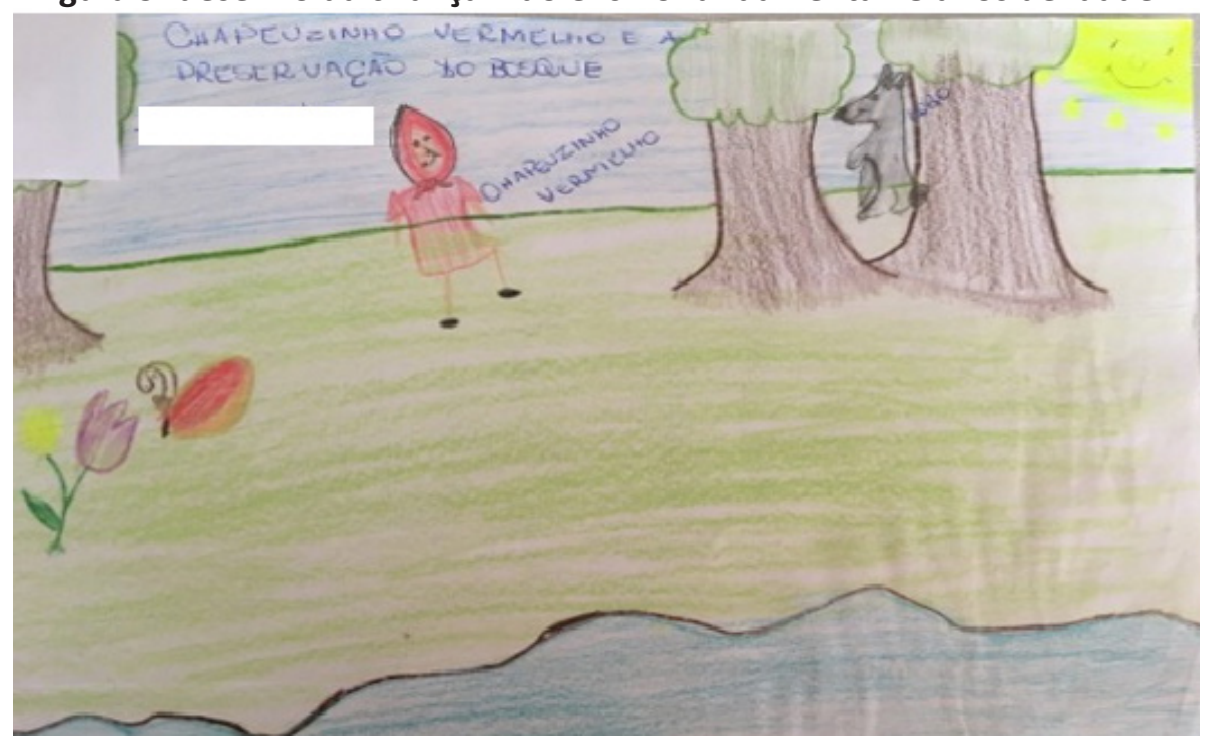

Fonte: Autoras, 2018

Ao observar o desenho da criança 4 do ensino fundamental também, 
é possível analisar que ela esteja no segundo estágio de esquemas, talvez em transição para o terceiro estágio o de representação verossímil. É possível perceber essa transição na representação gráfica da imagem da Chapeuzinho Vermelho na floresta, cuja figura humana ainda tem traços significativos do segundo estágio de esquemas, logo que os traços da cabeça, do dorso, das pernas e dos braços, não apresentam detalhes. Observa-se um aperfeiçoamento no desenho, em específico na imagem do lobo, mesmo tendo sido um personagem apenas citado no contexto da história. A criança o desenhou entre as árvores, de perfil, com características mais detalhadas, mostrando semelhanças ao real. Segundo Vigotski (2009), se essa criança estivesse por completo no segundo estágio, a representação do lobo teria traços de seres humanos, havendo dois olhos, mesmo ele estando de perfil. Por esse ponto, a criança está em transição de estágios.

\section{Figura 10: desenho da criança 5 do ensino fundamental - 8 anos de idade}

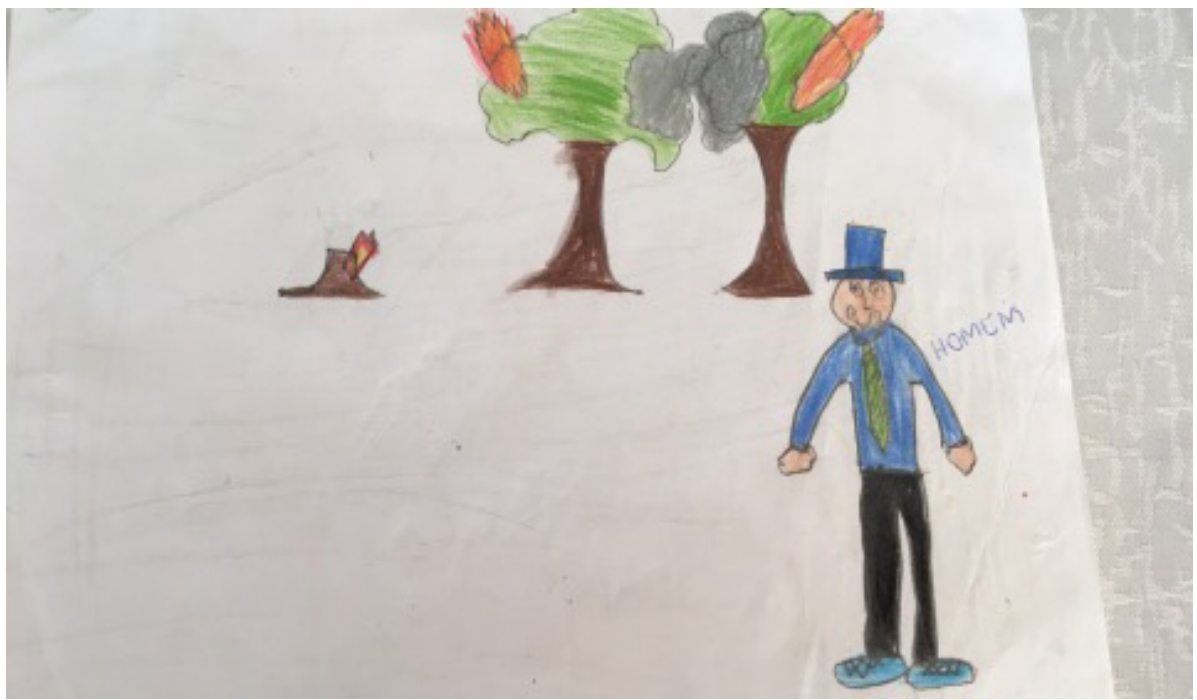

Fonte: Autoras, 2018

O desenho da criança 5 do ensino fundamental I, com o foco no momento em que as pessoas colocaram fogo na floresta, foi representado graficamente por apenas um homem e árvores em chamas. Pode-se observar e constatar que o terceiro estágio predomina de "representações verossímeis", quando se observa a imagem humana, com detalhes de roupas próximas ao real, por exemplo: a gravata, os detalhes no sapato, como se fossem cadarços. 
Vigotski (2009, p. 113) explica que no terceiro estágio é desenhado o objeto da forma como é visto. Uma representação ainda sem a plasticidade do real, no entanto é um desenho sem traços infantilizados.

Em relação ao terceiro estágio, é importante relatar o que Kerschensteiner (1854-1932 apud Vigotski 2009, p. 110) considera: “Muito poucas crianças [...] vão além do terceiro estágio com forças próprias, sem a ajuda do ensino".

Em vista dessas observações e análises dos desenhos das crianças do terceiro ano do ensino fundamental, pode-se concluir que são crianças as quais estão em transição de estágios e que realmente o meio social e a mediação se fazem necessários nesse processo. O desenho permite observar o desenvolvimento das crianças, não obstante essa atividade, muitas vezes, seja considerada inferior por profissionais ignorantes da importância do trabalho com desenhos para o desenvolvimento das funções superiores.

\section{Considerações finais}

Como se pode constatar nos experimentos realizados com as crianças, sua imaginação é mais pobre que a do adulto, por isso ela necessita de estímulos para aprender a desenvolver técnicas e recursos que lhe possibilitarão ampliar sua imaginação. Os estímulos precisam ser examinados e valorizados, porque promovem o desenvolvimento das funções psicológicas superiores (FPS).

O desenvolvimento das funções psicológicas superiores como atenção, memória, linguagem, abstração, pensamento, sensação, imaginação, pressupõem que tal desenvolvimento é promovido pela historicidade das relações humanas e pelo desenvolvimento da cultura. Isso requer que se considere a pré-história dessas funções, de suas raízes biológicas e das formas culturais básicas do comportamento humano, no qual se pode observar o emprego das ferramentas e a apropriação da linguagem. Ferramenta e linguagem/signos são elementos constituídos nas relações do gênero humano.

Seguindo os pressupostos teóricos e a complementação prática da análise, pode-se relatar como o outro é fundamental no desenvolvimento, isto é, todos são frutos de uma cultura, seres sociais e precisam da mediação para se desenvolver.

Dessa forma, é necessário um olhar diferenciado dos professores em relação ao desenho, já que é possível e essencial suas práticas terem como objetivos promover o desenvolvimento das crianças.

Muitas mudanças são necessárias na formação dos professores e, uma delas, refere-se ao conhecimento de estratégias as quais promovam o 
desenvolvimento intelectual dos pequenos. Essa pesquisa buscou demonstrar uma visão além da função de coordenação motora do desenho, mas como um recurso didático que deve ser utilizado com o propósito de desenvolver nas crianças muitas outras potencialidades para atingir níveis cada vez mais elevados de abstrações.

\section{Referências}

DUARTE, Newton. A Escola de Vigotski e a Educação Escolar: Algumas hipóteses para uma leitura pedagógica da psicologia Histórico Cultural. Psicologia USP. p.30-35 v.7, n.1-2, 1996. Disponível em: <https://www.revistas.usp.br/ psicousp/article/view/34531/37269>. Acesso em: 05 mar 2018.

LURIA, Alexander Romanovich. O desenvolvimento da escrita na criança. In: VIGOTSKI, Lev Semenovich. Linguagem, Desenvolvimento e Aprendizagem. ed. 11. São Paulo: Ícone, 2010, p. 143-189.

MOZZER, Geisa Nunes de Souza; BORGES, Fabrícia Teixeira. A criatividade infantil na perspectiva de Lev Vigotski. Inter. Ação. v.33, n 2, 2008. Disponível em: <https://www.revistas.ufg.br/interacao/article/view/5269/4314>. Acesso em: 21 dez 2017.

NATIVIDADE, Michelle Regina da. et al. Desenho na pesquisa com crianças: análise na perspectiva histórico-cultural. Contextos Clínicos. v.1, n.1 p.12, jun. 2008. Disponível em: http://pepsic.bvsalud.org/scielo.php?script=sci_arttext\&pid=S198334822008000100002>. Acesso em: 07 mar 2018.

OLIVEIRA, Marta Kohl de. Pensar a educação: contribuição de Vygotsky. In. CASTORINA, José Antonio. et. al. Piaget. Vygotsky: Novas contribuições para o debate. p.51-84. São Paulo: Editora Ática, 1996.

PETROVSKY, Arthur Vladimirovich. A imaginação. In: LONGAREZI, Andréa Maturano;

PUENTES, Roberto Valdés. org. Ensino desenvolvimental: livro 1. v.4 Uberlândia: Editora da Universidade Estadual de Uberlândia, 2017.

SANTOS, Naira Gomes de. Chapeuzinho Vermelho e a preservação do bosque. Editora Scipione, 2011.

SILVA, Silvia Maria Cintra da. A constituição social do desenho da criança. Campinas: Mercado das Letras, 2002. 
SILVA, Silvia Maria Cintra da. Condições sociais da constituição do desenho infantil. Psicologia USP. v.9, n.2. São Paulo, 1998. Disponível em: http://www. scielo.br/scielo.php?script=sci_arttext\&pid=S0103-65641998000200008> . Acesso em 10 mar 2018.

VYGOTSKI, Lev Semyonovich. A construção do pensamento e linguagem. 1. ed. São Paulo: Martins Fontes, 2001

VYGOTSKI, Lev Semyonovich. Imaginação e criação na infância. Apresentação e comentários: Ana Luiza Smolka; tradução Zoia Preste. São Paulo: Ática, 2009.

Data de recebimento: 30.01 .2019

Data de aceite: 01.06.2020 